\title{
Unintended Consequences of Gender Equality Promotion in Swedish Multicultural Contraceptive Counseling: A Discourse Analysis
}

Qualitative Health Research

I-II

(C) The Author(s) 2017

Reprints and permissions:

sagepub.com/journalsPermissions.nav DOI: 10.1 I77/10497323/7697099 journals.sagepub.com/home/qhr @SAGE

\author{
Jonna Arousell', Aje Carlbom², Sara Johnsdotter², Elin C. Larsson', \\ and Birgitta Essén
}

\begin{abstract}
In this article, we explore how reproductive health care providers in Sweden, a country often described as one of the most gender-equal countries in the world, incorporate gender equality ideals in multicultural contraceptive counseling. In the tension between gender equality promotion on one hand and respect for cultural diversity and individualized care on the other, we will demonstrate that values of gender equality were often given priority. This is not necessarily undesirable. Nevertheless, our proposal is that the gender equality ideology may inhibit providers' ability to think differently about issues at stake in contraceptive counseling, which may negatively influence women's possibilities to obtain adequate support. At the end of the article, we suggest how health care providers' reflexivity might be used as a working tool for increased awareness about the taken-for-granted cultural norms that exist in their clinical milieu.
\end{abstract}

\section{Keywords}

gender equality; cultural diversity; women; reproductive health; contraceptive counseling; discourse analysis; qualitative method; Sweden

\section{Introduction}

Together with the other Scandinavian citizenship regimes, Sweden is often described as one of the most gender-equal countries in the world (Thun, 2015; World Economic Forum, 2015; World Values Survey, 2016), where people usually give high priority to, for instance, shared parental leave, generous day-care opportunities for children, and women's participation in the labor market and political life (Månsdotter \& Deogan, 2016; World Values Survey, 2016). In contrast, increased migration to Sweden from non-Western countries where people, on average, express less support for gender equality between women and men (Kostenko, Kuzmuchev, \& Ponarin, 2016; Statistics Sweden, 2015; World Values Survey, 2016) has raised renewed attention to how gender equality aspects are being dealt with within multicultural welfare institutions (see Månsdotter \& Deogan, 2016; Thun, 2015). Of interest for empirical exploration in this article is how the "high-profiled ideal of gender equality" (Langvasbråten, 2008, p. 33) takes shape in the provision of reproductive health care in culturally diverse localities in Sweden, with contraceptive counseling as specific field of exploration. We asked, "With what motivations and strategies do clinicians communicate 'gender equality' in their encounters with non-Western women seeking contraceptive counseling, and what consequences may thereby arise?"

There is large consensus that increased gender equality between women and men will improve women's reproductive health (Gavriilidis et al., 2014; Grown, Gupta, \& Pande, 2005; World Health Organization [WHO], 2016). But "gender equality," as noted by many, is a framework without fixed content; instead, it is a discourse filled with a variety of meanings and often ambiguous proposals (Bacchi, 2009; Hammarström \& Annandale, 2012; van Eerdewijk \& Davids, 2014). It means that ideas of gender equality can be used for different purposes and therefore can lead to a variety of outcomes (Olivius, 2014). In this article, we explore health care providers' use of the gender equality norms "not as things with intrinsic meaning" (Olivius, 2014, p. 44), but as elastic and everyday strategies that were activated in attempts to govern women's

\footnotetext{
'Uppsala University, Uppsala, Sweden

${ }^{2}$ Malmö University, Malmö, Sweden

Corresponding Author:

Jonna Arousell, Department of Women's and Children's Health (IMCH), Uppsala University, 75I 85 Uppsala, Sweden.

Email: jonna.arousell@kbh.uu.se
} 
reproductive choices in certain directions. The gender equality ideology became, for providers interviewed during the course of our study, a lens through which the adequacy of women's reproductive choices were evaluated. Accordingly, contraceptive counseling was based not only on biomedical knowledge about available contraception but also on providers' moral judgments about whether, when, and how often women should reproduce. This is not necessarily undesirable. Yet we will suggest that when the gender equality ideology is given priority in contraceptive counseling, it may be at the expense of other principles in health care, those that emphasize respect, tolerance, and understanding for people's culturally diverse preferences and values.

\section{Gender Equality Ideology and Person-Centered Care}

In the field of global and public health, researchers have long and consistently been concerned about health disparities between women and men (Backhans, Lundberg, \& Mansdotter, 2007; Horton, 2015; Jonsson, Schmidt, Sparring, \& Tomson, 2006). Women are usually described as being particularly vulnerable due to gendered power structures (Gavriilidis et al., 2014). Regardless of whether empirical studies indicate that health outcomes are improved as a result of an increase in gender equality perspectives (Palència et al., 2014), or whether no or only ambiguous effects are seen (Kuhlmann \& Annandale, 2012; Påfs et al., 2015; Payne, 2014; Sörlin, Lindholm, Ng, \& Ohman, 2011), a predominant hypothesis is nevertheless that a society experiencing "true gender equality, with a simultaneous expansion of both men and women into previously gender-segregated spheres" (Backhans et al., 2007, p. 1902) will witness a gender-equal distribution in terms of health outcomes (Månsdotter \& Deogan, 2016). Scholars in the field appear to agree upon the overall objective: that increased gender equality is a much desirable component of a well-functioning reproductive welfare system (Allwood, 2013). "Gender equality" becomes, accordingly, as much an ideological concern as an empirical one, and an idiom used both to understand and guide political action. The perpetuating effect of gender equality ideas can now be observed in policy documents across the world (United Nations, 2014; UNWomen, 2016; WHO, 2015). The Swedish Government, as an example of relevance for this article, has, for several years, run the program "Gender Mainstreaming in Government Agencies" (GMGA). The program encompasses 59 government agencies and one organization that through the incorporation of "gender perspectives in all of their operations" work for a more gender-equal society (The Swedish Secretariat for Gender Research, 2016). The Swedish Public Health Agency, also taking part in the GMGA-program states in their action plan for gender mainstreaming that "women and men shall have the same possibilities and conditions with regard to education and paid work that create life-long independence" and that "women and men shall take the same responsibility for domestic work" (The Swedish Public Health Agency, 2015, p. 3). In what ways "gender equality" is related to health outcomes are not clarified in these policies, yet the task of incorporating gender equality, the Swedish Public Health Agency states, rests upon the welfare organizations working with clients "on the ground." Midwives in Swedish reproductive health care shall, accordingly, facilitate "equality between women and men" and are obliged to do so by paying "special attention to the woman and her child, in relation to their life conditions in society" (The Swedish Association of Midwives, 2016).

Left without much attention in these collective efforts for action to combat gender inequality is, however, the conflicting dimensions of other ideological ideas about how health care provision should be organized. An emergent set of research contributions are now emphasizing the value of "person-centeredness" and shared decision making in the provision of care (Miles \& Elliott, 2015). The benefits of person-centeredness are emphasized in recently launched educational material for health care personnel, jointly produced by a number of governmental agencies in Sweden. A respectful encounter, it says, requires that patients "are treated as individuals with a unique set of needs, preferences, and values in encounters with health care." Furthermore, health care providers must enable "meaningful participation by the patient in all aspects concerning his or her treatment" (The National Board of Health and Welfare, 2015a). It is useful to note that the overall objective of person-centeredness correlates well with ambitions in Swedish integration policies emphasizing the value of cultural and religious diversity (Prop. 1997/98:16, 1997). Swedish multicultural society shall encourage individuals "to be part of a greater totality, without needing to compromise their cultural and ethical identity" and that society "should therefore facilitate the individual to integrate old and new life patterns and lifestyles in the ways that he or she wants" (Prop. 1997/98:16, 1997, p. 23). In the provision of reproductive health care, clinicians should accordingly "show humbleness and respect for the patient's autonomy, integrity and dignity," "take the patient's and/or relatives' wishes into consideration," and "show openness and respect for different values and beliefs" (The National Board of Health and Welfare, 2006, p. 12).

That being said, here the outline of a conflict emerges: namely, that between gender equality promotion on one hand and cultural sensitivity and respect for individuals' own reproductive decisions on the other. The ideological tension can be presented as follows: ultimate respect for 
individuals' cultural and religious beliefs would, by definition, mean that all values - also those that cherish gender inequality rather than gender equality - would be welcomed. At the same time, this approach would be incompatible with the requirement stating that gender equality ideals should be given priority in the provision of reproductive health care (see Appelros, 2006; The Swedish Association of Midwives, 2016; The Swedish Public Health Agency, 2015). Health care personnel working in Swedish reproductive health care are positioned in the midst of this ideological tension. Following the sociologist Michael Lipsky (2010), this is, in itself, less remarkable: Being "between" conflicting and ambiguous policy claims is often part of welfare workers' daily struggles. Of analytical interest is, nevertheless, how these policies are transferred into practice and what consequences thereby arise (Bacchi, 2009).

\section{Method}

\section{Setting}

Contraceptive counseling in Sweden is offered in district health care centers, and in maternity, youth, and abortion clinics across the country. Often, contraception is made available at a subsidized cost according to each county council's local regulations, especially for women aged younger than 25 years. Midwives, and sometimes gynecologists, usually provide routine contraceptive counseling and prescription of contraception after face-to-face encounters with women or couples. The idea with the Swedish health care model has been to ensure that women can easily get in touch with health care providers who have expertise in reproductive health medicine. Thereby, patients should be able to obtain adequate support to make well-informed decisions about the available contraceptive methods and how to use them (Kopp Kallner, Thunell, Brynhildsen, Lindeberg, \& Gemzell Danielsson, 2015).

The recruitment of informants for this study was purposively directed to two county councils and foremost to residential areas with large migrant populations. Informants described that the majority of people in their clinics had a geographical background in the Northern and Eastern part of Africa and the Middle East. Some interviews were, however, conducted in locations having more equal proportions of Swedish-born and non-Western population groups.

\section{Participants}

Twenty-three providers (midwives and gynecologists/ obstetricians) working in four Swedish maternity, contraceptive, and abortion clinics were included in the study.
Five focus group discussions (FGDs) were conducted, comprising 2 to 8 individuals each. In addition, five individual semistructured interviews were conducted. All providers included in the study worked within contraceptive counseling and/or abortion care on a daily basis. Their length of time in the profession ranged from 3 to 17 years. One participant originally came from Iran, one participant was from Iraq (both having parents from their respective countries), and the remaining participants were born in Sweden to Swedish parents. As in many other countries, most clinicians working in Swedish contraceptive counseling are women. In general, few men work in the field of midwifery and contraceptive counseling in Sweden. This was also the case in the facilities selected for our study. To properly reflect the average gender composition, we, in this study, interviewed female providers.

\section{Procedure}

Individual interviews and FGDs were conducted by the first author. These took place in 2015. All interviews and FGDs except one were recorded and transcribed verbatim. Detailed notes were taken during the one interview that was not recorded, and these were given equal weight as the transcripts in the subsequent analysis. Interviews and FGDs followed a semistructured format and allowed for questions or discussions to be brought up openly during the conversation. FGDs lasted for approximately 1 hour each and were conducted at maternity/abortion clinics. Individual interviews ranged from 1 to 1.5 hours in length. All individual interviews, except one that took place in a café, as well as FGDs, were conducted at the informants' workplaces.

This study emerged as part of a larger project focusing on encounters between Muslim patients and reproductive health care providers in Swedish reproductive health care. In some cases, informants asked for clearance to talk about "immigrant" or "foreign-born" women instead of "Muslim women," as they felt they had little to say about religious aspects per se. Throughout the article, we will use the term "non-Western" women, as this appears to be the best alternative available to describe those individuals to whom the informants refer in their narratives. Initially, informants were asked to reflect upon "difficult" and "easy" situations in contraceptive counseling encounters and their experiences of providing care to patients with culturally diverse backgrounds. As the study progressed, the interview questions were refined to capture specific aspects of interest.

This study was approved by Uppsala Regional Ethics Board (Registration Number 2013/346) and was conducted in accordance with the principles of the Declaration of Helsinki. Informed consent was obtained from all 
informants. All informants quoted in this article have been given pseudonyms.

\section{Analysis}

The initial analysis of the data began by identifying the latent themes in the informants' narratives (see Braun \& Clarke, 2006). This was done by reading and rereading interview transcripts and by repeatedly listening to the audio recordings. In this process of interpretation (Ricoeur, 2011), a number of overarching themes were identified that potentially could add knowledge to already existing research (Bernard, 1996). One trend, however, was particularly widespread and strongly emphasized by informants in the first FGDs, namely, their sense that many non-Western female patients were reluctant to use contraception. To seek clarity in the underlying mechanisms thereof, we conducted additional interviews that paid extra attention to this particular aspect. We wanted to know, why did informants perceive this as a problem? And how did they deal with it in clinical encounters? The research process was thus inspired by what Lincoln and Guba (1985) would call "naturalistic inquiry," in which the understanding of a certain phenomenon develops as a result of subsequent data collection. In this process, FGDs provided knowledge about general tendencies and shared opinions among participants, while individual interviews served the purpose of probing in more depth about particular aspects of interest. The combination of methods for collecting data gave a good understanding of the issues at play, while also contributing with various depths of perspectives. FGDs and individual interviews were given equal weight in the subsequent analysis.

To delve further into the underlying logics supporting informants' descriptions of non-Western women's reluctance to use contraception, we used Carol Bacchi's framework, "What's the problem represented to be?" which is also called the What's the Problem Represented (WPR) approach, for subsequent analysis (Bacchi, 2009). Bacchi's (2009) point of departure is that "problems" do not exist as natural, objective, and readily identifiable phenomena that care providers, as in our study, are set to "solve" but that providers also produce "problems" with particular meanings (Bacchi, 2009). In our analytical process, the WPR approach helped us to illuminate "hidden" logics in providers' narratives, to thereby analyze which forces have generated certain actions to be taken in clinical practice (Bacchi, 2012). After interviews had been conducted, we used the step-by-step guide proposed by Bacchi in her WPR approach. This guide consists of a number of questions to "ask" the material to be analyzed. The WPR approach is thus not used to identify general, overarching themes but functions instead as an interpretative tool to "go deeper" into specific aspects of interest (see Braun \& Clarke, 2006). When adjusted for the analysis of our material, the guide progressed as follows:

1. What's the "problem" represented to be in providers' experiences of contraceptive counseling?

2. What presumptions or assumptions underpin this representation of the "problem"?

3. How has this representation of the "problem" come about?

4. What is left unproblematic in this representation of the "problem"? Where are the silences? Can the problem be thought of differently?

5. What effects/consequences are produced by this representation of the "problem"?

6. How/where has this representation of the "problem" been reproduced, and defended? How has it been questioned, disrupted, and replaced?

\section{Results}

The results will be presented largely in line with Bacchi's WPR approach. The fourth question in Bacchi's framework, that is, how the "problem" can be thought of differently, will be further developed in the Discussion section.

\section{What's the "Problem" Represented to Be in Providers' Narratives?}

When informants, both in individual interviews and in FGDs, were asked to reflect upon the difficulties they experienced in contraceptive counseling encounters, one specific problem was continually emphasized, namely, that non-Western women often appeared to be reluctant to use contraception. In one FGD, Sabina suggested that non-Western women seemed incapable of understanding the information given in contraceptive counseling encounters and of making adequate decisions based on it. No matter how hard she had tried to convince women about the benefits of using contraception, "[they] still want to continue with their withdrawals," she clarified. Other colleagues participating in the FGD supported Sabina, with most of them citing similar experiences or nodding in agreement. Many informants believed that non-Western women's low educational level and lack of insufficient sexuality education in the countries of origin could explain why it appeared difficult for them to use contraception in optimal ways. Adding to the discussion in the FGD, Zara said,

What I used to think about is what sort of knowledge one has about the body. Did they have any sort of sexuality education for example in ... [ . . ] I mean in Sweden we at least have some kind of . . . from early years in school, about how the body functions and all that. 
Importantly, and as also implied by Zara above, the participants did not experience the same difficulties in encounters with Swedish-born women. When compared with Swedish women's capability of receiving and making use of the information in a beneficial way, some informants represented non-Western women as more unreliable. As pointed out by Eva, "We don't dare to trust them in the way we do with Swedish women." In a subsequent individual interview, Cecilia revealed her sometimes-frustrated attempts to give adequate information about how to use the contraceptive method properly, only to realize that the women concerned got pregnant shortly after. "I believe that this probably has to do with their [non-Western women's] knowledge deficit about these matters [how to conceive]. That they really don't understand," she explained.

In general, informants expressed great concerns about this "unreliability" and distrust in non-Western women's capability to act in accordance with the contraceptive information given. The non-Western women's general reluctance to using contraceptives was thus, when viewed in light of Bacchi's WPR approach, represented to be the main "problem" in the informants' narratives.

\section{What Presuppositions or Assumptions Underpin This Representation of the "Problem"?}

The question, then, is, for what reasons did informants think that it was problematic that women did not use contraception? In the literature, often-mentioned reasons for the benefits of consistent contraceptive use are, for instance, to prevent unwanted pregnancies or sexually transmitted infections (Åkerman, Essen, Westerling, \& Larsson, 2016; Kopp Kallner et al., 2015). However, among the providers we interviewed, these were not the main concerns. Rather, they determined that inconsistent contraceptive practices increased the risk for women having large families, thus "trapping" women in the domain of the caring and nurturing home.

Some informants were afraid that having too many children could obstruct non-Western women's chances of obtaining an education, starting employment, or being part of social life in Sweden. In one of the FGDs, participants were asked to elaborate on why they thought this was important. Initially, Karin and Frida explained that it is imperative for the woman to get a sense of belonging and coherence; if a woman must stay at home most of the time due to having too many children, she would "never get into a real social context," Karin said. This point was followed up by Frida, who emphasized that women who had migrated should preferably enroll in further education to obtain a job once living in Sweden:
[Although] she is not used to it, but it is obvious that it's quite difficult to manage in Sweden in case not both persons are working. That it will be like ... that the man is handling that [working] and the woman takes care of things at home. And that does not work here.

Other informants also emphasized the need of equal division of household tasks versus paid labor between husband and wife. In a subsequent individual interview, Ingrid told how she had seen on several occasions sad examples of how women came to suffer from having too many children to care for. Being part of Swedish society, she argued, requires a lot of participation and engagement from parents, which could risk putting too great a burden upon the mother in terms of child rearing:

They grow up and they go to school, that we all know, right, and they demand time, extremely much time. And I just think that ... If one has eight children and pretty close to each other, imagine having eight homework preparations every day, and it is a high pressure [on parents] that they should be present and all that. And if you don't have that much education yourself, how will it then work out? This is what I feel is so reckless if I dare to say so. But, "Dear, you must want your children to succeed and that they shall" ... yes, you know, in the future and all.

To prevent women from jeopardizing their freedom, as well as hinder their children's opportunities to succeed in the future, Ingrid explained that one should carefully consider how many children it is appropriate to have: "If I shall give an idea about this, I would say ... [...]. Yeah, around three children might be the most optimal number." By limiting the number of children, she came to conclude, it would be possible for women living in Sweden to have a family but yet be able to engage in activities outside the reproductive/nurturing sphere.

\section{How Has This Representation of the "Problem" Come About?}

When talking to informants, it soon became clear that the "problem" and the concerns attached to non-Western women's contraceptive practices came into being in a clinical context where gender equality and women's rights perspectives had a very prominent position. Informants said that they became both sad and frustrated when noticing that husbands made decisions about contraceptive practices above the wishes of their wives. For many, this was connected with considerable emotional difficulties in understanding and tolerating patriarchal structures that gave husbands' views priority over their wives'. The difficulties were situated, as exemplified by Ann-Sofie, in the idea "that the husband is self-appointed as being the lord of the house, and sort of directs and 
dictates [the rules]." Ann-Sofie described how, on several occasions, a couple might arrive at the clinic, and the husband would request that the wife's intrauterine device (IUD) was removed. A hypothetical scenario, she explains, could unfold as follows:

[It is possible that] the woman says that the husband wants it, and then I ask, "Do you want another contraceptive method?" No, they don't want. And do they want more children? Yes, he wants more children. That is very, very common [that the husband wants more children, but the wife does not]. And if the husband is there, I can tell him that, "It is very important that your wife is allowed to express her view, that she does what she wants." If she does not want to remove her IUD, she should not be forced to do it.

For Ann-Sofie, situations such as these become what she described as "very complicated." When asked to expand on why it could become problematic for her to manage, she explained that is painful to see "that the woman does not have any rights to decide over her body herself, when she feels ready for a pregnancy. [When] she does not have any possibilities to claim her rights or her views."

Informants' continuous references to women's rights to make decisions about their own bodies were primarily understood in terms of liberation from male patriarchy, ideas that are strongly interlinked with what, for instance, Ingrid phrased as a type of "feminist struggle." Ingrid said that, in Sweden, the progress in women's rights, gender equality, and feminist perspectives has come far, and she found this advancement very desirable. Carina, another midwife who was also interviewed individually, explained that discussions about feminism and the advantages of gender equality had always been part of her private life, and still is. Now-when working in contraceptive counseling - it also became a central objective when actively trying to promote women's sexual and reproductive rights.

\section{What Effects/Consequences Are Produced by This Representation of the "Problem"?}

In various ways, the gender equality approach became a motif for informants to compel non-Western women to use contraception. First, providers seemed to take responsibility for pursuing women to make adequate decisions on whether, when, and how often to have children. From informants' perspectives, this strategy was rarely viewed as an infraction upon the woman but rather as a justified tool used for "saving" non-Western women from the underlying structures of patriarchal oppression executed by their husbands. These persuasion techniques appeared to be used regardless of whether women came alone or accompanied by their husbands. One participant in an
FGD received support from others in the group when pointing out that

so, if a woman comes here, if she is older and already has five, six, seven children and we can see that she is tired and worn-out, yes, then we say: "Yeah, but do you really want more children, maybe we should insert an IUD or something that you really swallow?" but then it comes, the resistance.

As the informant above illustrates, a common trend reported in the interviews was the experience that nonWestern women often resisted providers' "empowering" attempts or that they were reluctant to listen to the information provided in contraceptive counseling encounters. Therefore, informants alluded, they had to be creative to make the woman understand the importance of consistent contraceptive use. Magdalena, participating in one of the FGDs, told how she once sought help from a colleague when sensing that she was unable to convince a newly migrated woman about the benefits of proper family planning. She recalled what had been said:

And I said [to the woman]: "No, but maybe it is best that you don't get more children right now, you need to learn Swedish," and she just said: "Yes, but my husband knows Swedish." But we have an assistant nurse who is Kurdish and Muslim herself and she was able to better explain that, "It doesn't really work like that in Sweden, both need to work."

To "educate" non-Western women about how a fruitful integration into Swedish society would require a nottoo large family and a shared responsibility between husband and wife with regard to labor work and domestic work, appeared to be a legitimized and realistic approach among informants. This strategy also involved a high degree of moral persuasion: as the quota above illuminates, the female patient appeared explicit that her personal need to learn Swedish and enter the labor market was less urgent, as she could rely on her husband. Nevertheless, Magdalena found this problematic and ensured that another colleague attempted to talk the female patient into getting back on the "right track."

Beyond this type of moral persuasion, another strategy used by informants to increase the likelihood of women using contraception was to simplify or leave out information about the available contraception methods and how they functioned in the body. Doing so, informants explained, was a way of making information individualized and adjusted to the woman's assumed needs. If Carina, for instance, gives contraceptive counseling to a non-Western woman who she believes has a generally low level of knowledge about contraceptives and bodily functions, the information she gives may come to deviate from her usual approach: 
Like ... I don't get as nuanced as I usually am, I tend to . . . [I don't] inform about all possible types of hormonal contraception, for example, but I become . . . I simplify, I believe, if I should be a bit critical.

Informants' concerns about non-Western women's incapability or reluctance to use contraception thus generated two practical effects: either informants tried by persuasion to convince women about the benefits of using contraception and thereby plan the family size, or, as some informants explained, by tailoring or simplifying information about the available contraception methods.

\section{How/Where Has This Representation of the "Problem" Been Reproduced and Defended? How Could It Be Questioned, Disrupted, and Replaced?}

The representation of the "problem" of non-Western women's reluctance to use contraception was reproduced in both individual interviews and in focus group interviews. Many informants agreed with each other that nonWestern women often appeared incapable of making sense of the information given in contraceptive counseling, and of making adequate reproductive choices in accordance with it. Likewise, they were in consensus about promoting increased gender equality, for example, that making it possible for women to educate themselves, enter into the labor market, and become more financially self-sustaining, would have a positive spin-off effect on reproductive life choices. In an individual interview, Ingrid suggested that

if you have many children you won't have time to go to school, you don't have time to educate yourself. And a lot of good things come with education. It is . . proven that women who are educated give birth to less children, for example. Both because she doesn't have time and also because she is ... schooled, and then she will know about what sort of rights she has and ... And plus that she understands [how contraceptives function in the body].

With all good intentions, informants such as Ingrid pushed through their ideas about what a "good life" entails in encounters with women. Nevertheless, informants seemed to engage in this educational or persuasive process, because they cared a lot about their patients' future life in Sweden. Most informants did not appear to find these "convincing attempts" to be very problematic. Quite the opposite: If they avoided informing women about gender equality and their reproductive freedom, they seemed concerned that their silences would implicitly legitimize the hidden structures of patriarchal oppression.
In one FGD in particular we could, however, identify ways in which this representation of the problem became partly questioned. Here, Carina, Mira, and Felicia began talking about the tension they often experienced between patients' contraceptive choices and their own medical knowledge and experience of "what works." Felicia started off by saying that it might be an oversimplified explanation that non-Western women for various reasons are incapable of using contraceptives, making the whole situation what she calls "double-edged": Although having knowledge about what works and not in terms of contraceptives, "we should also not override someone's desire to wanting to have it in a special way," she continued. In the conversation that followed in the FGD, Mira and Felicia problematized who - the woman or the midwives themselves - should have the "last say" in relation to whether women should use contraceptives:

Mira: I agree, we must counsel as if it is the woman who decided right now.

Felicia: It is not us who should decide, it is the woman.

Mira: Yes, that they should be part of the decision.

Subsequently, Carina agreed that placing a stronger focus on individual women's concerns would help clarify their personal reproductive desires. Yet she also said that it could be difficult to always probe as deeply in counseling encounters, partly due to time constraints. "We need to have enough time, and we need to maintain an interest in every individual woman. It is . . fantastic when one has that," she said. In the best of worlds, Carina continued, health care providers should always have enough time to really understand who the woman is and "what you want and how it can be made good." But due to the general lack of resources, Carina insinuated, there is a risk that she and her colleagues sometimes miss out on exploring the depth of patients' own perspectives.

\section{Discussion}

The results presented in this article illuminate the complexity of mainstreaming gender equality into contraceptive counseling in Swedish multicultural society. We have demonstrated that it proves to be difficult for health care providers who are ideologically motivated to promote gender equality in clinical encounters, to simultaneously value, respect, and tolerate cultural traditions that are considered to uphold gender-unequal or patriarchal family structures. The tension between the gender equality ideology and a person-centered care approach where cultural differences are tolerated thus proved to produce a practical solution: The right for individuals to nurture and maintain religious and cultural beliefs may be assured in some cases, but not if people express values that pertain 
Table I. Summary of Findings.

What's the "problem" represented to be?

- Non-Western women's reluctance to use contraceptives

What assumptions underpin this representation of the "problem"?

- Having large families traps women in the caring home domain, preventing them from being liberated and free from male patriarchy

How has this representation of the "problem" come about?

- In a clinical/societal context where gender equality/ women's rights perspectives have a very prominent position

What effects/consequences are produced by this representation of the "problem"?

- Providers make efforts to persuade women to make different choices

- Information about available contraception is left out to make information easier to embrace

How/where has this representation of the "problem" been reproduced /. . ./ and questioned?

- Reproduced and disseminated in both focus groups and individual interviews

- Questioned by informants proposing that more attention/ understanding of women's circumstances are needed

to gender inequality. The gender equality standard is thus one example of a liberal, egalitarian value that some policy makers and - in our example - health care providers appear to give priority to at the expense of others (for a summary of findings, see Table 1).

That gender equality promotion is given priority over principles of self-governance and respect for religious and cultural diversity is, however, not necessarily undesirable. Are perhaps policy makers, researchers, and welfare workers, as also pointed out by Appelros (2006), "simply forced to accept that a democratic society also chooses its values and prescribes for its citizens what is acceptable and what is not" (pp. 212-213)? Some scholars in the field of reproductive health do not deny the necessity of moral persuasion in clinical encounters, in terms of "influencing, convincing, pleading your case, and ultimately changing someone's mind or making someone believe differently" (Lothian, 2009, p. 41) in case clinicians want to change people's behavior (Lothian, 2009). If patients with diverse cultural and religious backgrounds are continuously exposed to the majority society's predominant attitudes regarding sexual liberation and gender equality, it might facilitate a faster adaptation to the new societal context (Norris \& Inglehart, 2012). Norris and Inglehart (2012) have, for instance, suggested that Muslims who have moved to Western countries from non-Western regions tend to "gradually absorb the values prevalent in their host society" (p. 231). These examples all talk in favor of "gender mainstreaming" in the provision of care.
But there are evidently other aspects in relation to women's contraceptive practices that are silenced by the gender equality ideology's dominance. Following the fourth question in Carol Bacchi's WPR approach, what would happen if the "problem" represented to be in providers' narratives - that is, non-Western women's perceived reluctance to use contraception - would be thought about differently? Or what would happen if it is not thought of as a "problem" at all (Bacchi, 2009)? Viewing the "problem" from different perspectives illuminates situations in which gender equality promotion could potentially serve as barriers to women's access to appropriate contraceptive methods:

First, new perspectives will arise if we consider that the task of promoting better gender equality should rest upon politicians or social activists - not on health care providers. The central question is, thus, to what extent should public health care institutions seek to provoke change in people's private lives to make them more gender equal (see also Graham, McKenzie, Lamaro, \& Klein, 2016, for a discussion about persuasive ideologies in Australian reproductive health policies). The plausible risk of granting generous space for health care providers to give advice in accordance with their ideological convictions about gender equality is that the content of contraceptive counseling sessions could become very unreliable. West-Oram and Buyx (2016, p. 336) have, in a recent publication, discussed a "worrying trend in healthcare policy" in Western countries, namely, that women's reproductive rights to autonomous decisions are increasingly challenged by principles favoring clinicians' rights not to provide care that violates their personal ideological beliefs (West-Oram \& Buyx, 2016). If ideological beliefs are given priority, it could exemplify what some scholars would probably define as a type of paternalism (De Zordo, 2012; Irmak, 2016; Larivaara, 2010), in light of which providers are enabled to "expand their own view of the good into the public arena, thereby restricting the freedoms of other people to live according to their own views of the good" (West-Oram \& Buyx, 2016, p. 340). This could plausibly endanger patients' perceptions of contraceptive counseling as reliable, trustworthy, and evidence-based, and, in a worst-case scenario, influence peoples' willingness to seek care (see Higgins, Kramer, \& Ryder, 2016).

Second, similar conclusions arise when we consider that women are capable (as opposed to incapable) of receiving, evaluating, and making choices based on the information they receive about different contraceptive methods. If so, there would be few reasons for providers to actively ensure that women make "correct" decisions (see den Hartogh, 2016). Rather, it would be sufficient that providers give nothing else but standard evidencebased information about available contraceptives - just 
as they are obliged to do (The National Board of Health and Welfare, 2006, 2015b). However, as implied by some informants in our study, the desire to compel women to use contraception could cause more limited and simplified information about different contraceptive methods and their respective function in the body to be provided. This provider strategy exemplifies how gender equality norms per se potentially could function as a barrier with regard to women's access to contraceptive information.

Third, the tendency among providers to interpret the "problem" of non-Western women's contraceptive practices - as well as the solutions thereto-in terms of gender inequality could silence any other aspect of importance for women's contraceptive decisions (Bacchi, 2009). The risk of overemphasizing gender inequalities as a particularly urgent issue in contraceptive counseling is that alternative aspects remain unexplored. Viewed from this perspective, one could argue that the gender equality ideology may serve as an obstructing factor that providers would need to look beyond, rather than promote, to properly understand what is at stake for the person they meet (Kleinman \& Benson, 2006).

\section{Reflexivity as Part of Clinical Work: Some Implications for Practice}

The work of medical anthropologist Arthur Kleinman on the "cultural construction of clinical reality" can provide a better understanding of why informants in our study, without much hesitation, represented non-Western women's reluctance to use contraception as problematic (Kleinman, Eisenberg, \& Good, 1978). Both patients and health care providers, Kleinman and Benson (2006) proposed, carry with them experiences of health and ill health that are shaped by the cultural repertoires available to them. The gender equality ideology is one example of a cultural construct that informants made use of to label and evaluate conditions they encountered as "healthy" or "un-healthy"; "good" or "bad" (Kleinman \& Benson, 2006). In other words, providers are also part of cultural systems of thoughts and norms, although these are often taken for granted and seldom problematized. Recent publications have suggested that more reflexivity among clinicians in health care may help to question the "silent" assumptions underlying clinical understandings of certain matters (Liberati et al., 2015). This could, for example, be done by critically examining the "problems" one encounters in clinical practice. One might ask, what is this "problem" actually about? Why is this a "problem," and for whom? Why do I believe that this is a problem? How can the "problem" be thought of differently (Bacchi, 2012; Loseke, 2003)? If so, many new perspectives may arise. This suggestion should not be misunderstood as an
Table 2. Reflexivity as Part of Clinical Practice.

- Aims at unpacking taken-for-granted cultural assumptions underpinning clinical practice

- Can be carried through with help from "problematizations"

- Ultimately facilitates providers and patients to make their respective positions/expectations clear to themselves and to each other

encouragement for providers to give up their moral convictions about the benefits of gender equality but rather as a call for increased awareness that they do adhere to culture-specific norm systems themselves. The aim of doing so would ultimately be that both patients and providers can make their positions in relation to a certain matter clear to themselves and to each other and thereafter discuss what solutions are at hand (Kleinman \& Benson, 2006; Kleinman et al., 1978) (see Table 2).

\section{Conclusion}

In this article, we have shown that the incorporation of gender equality perspectives in Swedish contraceptive counseling may compromise other principles in health care, such as respect, tolerance, and understanding of people's culturally diverse preferences and values. That the gender equality ideology is given priority is not necessarily undesirable but nevertheless appears to generate unintended consequences. Our main proposal is that the gender equality ideology may inhibit providers' ability to think differently about issues at stake in contraceptive counseling. If clinicians are not open to alternative perspectives, it could negatively influence women's possibilities to obtain adequate support in relation to individual reproductive desires or hindrances.

\section{Acknowledgments}

The authors would like to thank all health care clinicians who participated in this study.

\section{Declaration of Conflicting Interests}

The authors declared no potential conflicts of interest with respect to the research, authorship, and/or publication of this article.

\section{Funding}

The author(s) disclosed receipt of the following financial support for the research, authorship, and/or publication of this article: The research and the publication was funded by the Swedish Research Council for Health, Working Life and Welfare (FORTE), Stiftelsen familjeplaneringsfonden Uppsala, and the Faculty of Medicine at Uppsala University, Sweden. 


\section{References}

Åkerman, E., Essen, B., Westerling, R., \& Larsson, E. (2016). Healthcare-seeking behaviour in relation to sexual and reproductive health among Thai-born women in Sweden: A qualitative study. Culture, Health \& Sexuality, 19, 194207. doi:10.1080/13691058.2016.1214746

Allwood, G. (2013). Gender mainstreaming and policy coherence for development: Unintended gender consequences and EU policy. Women's Studies International Forum, 39, 42-52. doi:10.1016/j.wsif.2013.01.008

Appelros, E. (2006). Religion som ideologiskt styrmedel [Religion as ideological governing tool]. In J. Modée \& H. Strandberg (Eds.), Frihet och gränser. Filosofiska perspektiv på religionsfrihet och tolerans [Freedom and limitations: Philosophical perspectives on freedom of religion and tolerance]. Stockholm, Sweden: Brutus Östlings Bokförlag Symposion.

Bacchi, C. (2009). Analysing policy: What's the problem represented to be? Frenchs Forest, Australia: Pearson.

Bacchi, C. (2012). Why study problematizations? Making politics visible. Open Journal of Political Science, 2, 1-8.

Backhans, M. C., Lundberg, M., \& Mansdotter, A. (2007). Does increased gender equality lead to a convergence of health outcomes for men and women? A study of Swedish municipalities. Social Science \& Medicine, 64, 1892-1903. doi:10.1016/j.socscimed.2007.01.016

Bernard, H. R. (1996). Qualitative data, quantitative analysis. The Cultural Anthropology Methods Journal, 8, 9-11.

Braun, V., \& Clarke, V. (2006). Using thematic analysis in psychology. Qualitative Research in Psychology, 3, 77-101. doi:10.1191/1478088706qp063oa

De Zordo, S. (2012). Programming the body, planning reproduction, governing life: The "(ir-) rationality" of family planning and the embodiment of social inequalities in Salvador da Bahia (Brazil). Anthropology \& Medicine, 19, 207-223. doi:10.1080/13648470.2012.675049

den Hartogh, G. (2016). Do we need a threshold conception of competence? Medicine, Health Care and Philosophy, 19, 71-83. doi:10.1007/s11019-015-9646-5

Gavriilidis, G., Gavriilidou, N., Pettersson, E., Renhammar, E., Balkfors, A., \& Östergren, P.-O. (2014). Empowerment evaluation of a Swedish gender equity plan. Global Health Action, 7, Article 23710. doi:10.3402/gha.v7.23710

Graham, M., McKenzie, H., Lamaro, G., \& Klein, R. (2016). Women's reproductive choices in Australia: Mapping federal and state/territory policy instruments governing choice. Gender Issues, 33, 335-349. doi:10.1007/s12147016-9159-4

Grown, C., Gupta, G., \& Pande, R. (2005). Taking action to improve women's health through gender equality and women's empowerment. The Lancet, 365, 541-543. doi:10.1016/S0140-6736(05)17872-6

Hammarström, A., \& Annandale, E. (2012). A conceptual muddle: An empirical analysis of the use of "sex" and "gender" in "gender-specific medicine" journals. PLOS ONE, 7, e34193. doi:10.1371/journal.pone.0034193

Higgins, J., Kramer, R., \& Ryder, K. (2016). Provider bias in long-acting reversible contraception (LARC) promotion and removal: Perceptions of young adult women. American Journal of Public Health, 106, 1932-1937.

Horton, R. (2015). Offline: Gender equality-The neglected SDG for health. The Lancet, 386, 1928.

Irmak, N. (2016). Right to refuse treatment in Turkey: A diagnosis and a slightly less than modest proposal for reform. Journal of Medical Ethics, 42, 435-438. doi:10.1136/ medethics-2015-103266

Jonsson, P. M., Schmidt, I., Sparring, V., \& Tomson, G. (2006). Gender equity in health care in Sweden-Minor improvements since the 1990s. Health Policy, 77, 24-36. doi:10.1016/j.healthpol.2005.07.012

Kleinman, A., \& Benson, P. (2006). Anthropology in the clinic: The problem of cultural competency and how to fix it. PLoS Medicine, 3, e294. doi:10.1371/journal.pmed.0030294

Kleinman, A., Eisenberg, L., \& Good, B. (1978). Culture, illness, and care: Clinical lessons from anthropologic and cross-cultural research. Annals of Internal Medicine, 88, 251-258

Kopp Kallner, H., Thunell, L., Brynhildsen, J., Lindeberg, M., \& Gemzell Danielsson, K. (2015). Use of contraception and attitudes towards contraceptive use in Swedish women: A nationwide survey. PLoS ONE, 10, e0125990. doi:10.1371/ journal.pone. 0125990

Kostenko, V., Kuzmuchev, P., \& Ponarin, E. (2016). Attitudes towards gender equality and perception of democracy in the Arab world. Democratization, 23, 862-891. doi:10.108 0/13510347.2015.1039994

Kuhlmann, E., \& Annandale, E. (2012). Mainstreaming gender into healthcare: A scoping exercise into policy transfer in England and Germany. Current Sociology, 60, 551-568.

Langvasbråten, T. (2008). A Scandinavian Model? Gender equality discourses on multiculturalism. Social Politics: International Studies in Gender, State and Society, 15, 32-52. doi:10.1093/sp/jxn005

Larivaara, M. M. (2010). Pregnancy prevention, reproductive health risk and morality: A perspective from public-sector women's clinics in St. Petersburg, Russia. Critical Public Health, 20, 357-371. doi:10.1080/09581590903436895

Liberati, E. G., Gorli, M., Moja, L., Galuppo, L., Ripamonti, S., \& Scaratti, G. (2015). Exploring the practice of patient centered care: The role of ethnography and reflexivity. Social Science \& Medicine, 133, 45-52. doi:10.1016/j.socscimed.2015.03.050

Lincoln, Y. S., \& Guba, E. G. (1985). Naturalistic inquiry. Beverly Hills, CA: Sage.

Lipsky, M. (2010). Street level bureaucracy: Dilemmas of the individual in public services (30th anniversary expanded ed.). New York: Russell Sage.

Loseke, D. (2003). Thinking about social problems. New Brunswick, NJ: Transaction Publishers.

Lothian, J. A. (2009). Persuasion: The key to changing women's ideas about birth. The Journal of Perinatal Education, 18, 41-44. doi:10.1624/105812409X474807

Månsdotter, A., \& Deogan, C. (2016). Further gender equality-Is it good or bad for sexual health? Journal of Gender Studies, 25, 294-302. doi:10.1080/09589236.2014.964668

Miles, A., \& Elliott, J. (2015). The European Society for Person Centered Healthcare (ESPCH) - Raising the bar of 
health care quality in the century of the patient. Journal of Evaluation in Clinical Practice, 20, 729-733.

The National Board of Health and Welfare. (2006). Kompetensbeskriving för legitimerad barnmorska [Competence description for authorized midwife]. Socialstyrelsen.

The National Board of Health and Welfare. (2015a). Att mötas $i$ hälso- och sjukvård. Ett utbildningsmaterial för reflektion om bemötande och jämlik vård [Encounters in healthcare: An education material for reflections about encounters and equal care]. Socialstyrelsen.

The National Board of Health and Welfare. (2015b). Målbeskrivningar i läkarnas ST (SOSFS 2008:17)/Obstetrik och gynekologi [Competence description for medical doctors' specialization (SOSFS 2008:17)/obstetrics and gynecology]. Socialstyrelsen.

Norris, P., \& Inglehart, R. F. (2012). Muslim integration into Western cultures: Between origins and destinations. Political Studies, 60, 228-251. doi:10.1111/j.14679248.2012.00951.x

Olivius, E. (2014). Governing refugees through gender equality: Care, control, emancipation (Doctoral thesis). Umeå University, Umeå, Sweden.

Påfs, J., Musafili, A., Binder-Finnema, P., Klingberg-Allvin, M., Rulisa, S., \& Essen, B. (2015). "They would never receive you without a husband": Paradoxical barriers to antenatal care scale-up in Rwanda. Midwifery, 31, 11491156. doi:10.1016/j.midw.2015.09.010

Palència, L., Malmusi, D., De Moortel, D., Artazcoz, L., Backhans, M., Vanroelen, C., \& Borrell, C. (2014). The influence of gender equality policies on gender inequalities in health in Europe. Social Science \& Medicine, 117, 25-33. doi:10.1016/j.socscimed.2014.07.018

Payne, S. (2014). Gender mainstreaming as a global policy paradigm: Barriers to gender justice in health. Journal of International and Comparative Social Policy, 30, 28-40. doi:10.1080/21699763.2014.886609

Prop. 1997/98:16. (1997). Sverige, framtiden och mångfalden - från invandrarpolitik till integrationspolitik [Sweden, the future and pluralism-From immigration politics to integration politics]. Näringsdepartementet [The Ministry of Enterprise and Innovation].

Ricoeur, P. (2011). Homo Capax: texter av Paul Ricouer om etik och filosofisk antropologi [Homo Capax: Texts by Paul Ricoeur on ethics and philosophical anthropology]. Göteborg, Sweden: Bokförlaget Daidalos.

Sörlin, A., Lindholm, L., Ng, N., \& Ohman, A. (2011). Gender equality in couples and self-rated health: A survey study evaluating measurements of gender equality and its impact on health. International Journal for Equity in Health, 10, Article 37. doi:10.1186/1475-9276-10-37

Statistics Sweden. (2015). Invandringar efter födelseland och år [Immigration in accordance to country of birth and year]. Retrieved from http://www.statistikdatabasen.scb.se/pxweb/ sv/ssd/START_BE_BE0101_BE0101J/ImmiEmiFod/ table/tableViewLayout1/?rxid=f55 f0fd4-7048-41f3-b4444507cabbeddd
The Swedish Association of Midwives. (2016). Barnmorskan [The midwife]. Retrieved from http://www.barnmorskeforbundet.se/barnmorskan/

The Swedish Public Health Agency. (2015). Handlingsplan för jämställdhetsintegrering på Folkhälsomyndigheten 20162018 [Action plan for gender mainstreaming at the public health agency 2016-2018]. Folkhälsomyndigheten.

The Swedish Secretariat for Gender Research. (2016). GMGA: Gender mainstreaming in government agencies. Retrieved from http://www.genus.se/en/about-us/our-assignments/gmga/

Thun, C. (2015). Inclusive and women-friendly in a time of diversity? The Scandinavian citizenship regime-The "childcare lesson.” NJSR: Nordic Journal of Social Research, 6, 1-22.

United Nations. (2014). Gender equality and sustainable development: A pathways approach. New York: UNWomen.

UNWomen. (2016). Gender mainstreaming. Retrieved from http://www.un.org/womenwatch/osagi/gendermainstreaming.htm

van Eerdewijk, A., \& Davids, T. (2014). Escaping the mythical beast: Gender mainstreaming reconceptualised. Journal of International Development, 26, 303-316. doi:10.1002/ jid. 2947

West-Oram, P., \& Buyx, A. (2016). Conscientious objection in healthcare provision: A new dimension. Bioethics, 30, 336-343. doi:10.1111/bioe.12236

World Economic Forum. (2015). The global gender gap report 2015. Retrieved from http://reports.weforum.org/globalgender-gap-report-2015/

World Health Organization. (2015). Roadmap for action: Integrating equity, gender, human rights, and social determinants into the work of WHO. Geneva, Switzerland: Author.

World Health Organization. (2016). A foundation to address equity, gender and human rights in the 2030 agenda: Progress in 2014-2015. Geneva, Switzerland: Author.

World Values Survey. (2016). Findings and Insights. Retrieved from http://www.worldvaluessurvey.org/WVSContents. jsp?CMSID $=$ Findings

\section{Author Biographies}

Jonna Arousell, $\mathrm{MSc}, \mathrm{PhD}$ candidate in International Reproductive and Maternal Health at the Department of Women's and Children's Health at Uppsala University, Sweden.

Aje Carlbom, $\mathrm{PhD}$, associate professor in social anthropology at the Faculty of Health and Society at Malmö University, Sweden.

Sara Johnsdotter, $\mathrm{PhD}$, professor in medical anthropology at the Faculty of Health and Society at Malmö University, Sweden.

Elin C. Larsson, $\mathrm{PhD}$, post-doc in International Reproductive and Maternal Health at the Department of Women's and Children's Health at Uppsala University, Sweden.

Birgitta Essén, $\mathrm{PhD}$, professor in International Reproductive and Maternal Health at the Department of Women's and Children's Health at Uppsala University, and Senior Consultant in Obstetrics and Gynecology at the University Hospital of Uppsala, Sweden. 